\title{
Comparative mortality of hemodialysis patients at for-profit and not-for-profit dialysis facilities in the United States, 1998 to 2003: A retrospective analysis
}

\author{
Robert N Foley*1,2, Qiao Fan11, Jiannong Liu1 ${ }^{1}$, David T Gilbertson1, \\ Eric D Weinhandl ${ }^{1}$, Shu-Cheng Chen ${ }^{1}$ and Allan J Collins ${ }^{1,2}$
}

Address: ${ }^{1}$ United States Renal Data System, 914 South 8th Street, Suite S-406, Minneapolis, Minnesota, USA and ${ }^{2}$ Department of Medicine, Phillips-Wangensteen Building, University of Minnesota, Minneapolis, Minnesota, USA

Email: Robert N Foley* - RFoley@usrds.org; Qiao Fan - QFan@usrds.org; Jiannong Liu - JLiu@usrds.org;

David T Gilbertson - DGilbertson@usrds.org; Eric D Weinhandl - EWeinhandl@usrds.org; Shu-Cheng Chen - SChen@usrds.org; Allan J Collins - ACollins@usrds.org

* Corresponding author

Published: 26 June 2008

BMC Nephrology 2008, 9:6 doi:10.1 I86/147/-2369-9-6

This article is available from: http://www.biomedcentral.com/I47I-2369/9/6

(c) 2008 Foley et al; licensee BioMed Central Ltd.

This is an Open Access article distributed under the terms of the Creative Commons Attribution License (http://creativecommons.org/licenses/by/2.0), which permits unrestricted use, distribution, and reproduction in any medium, provided the original work is properly cited.
Received: 2 October 2007

Accepted: 26 June 2008

\begin{abstract}
Background: Concern lingers that dialysis therapy at for-profit (versus not-for-profit) hemodialysis facilities in the United States may be associated with higher mortality, even though 4 of every 5 contemporary dialysis patients receive therapy in such a setting.
\end{abstract}

Methods: Our primary objective was to compare the mortality hazards of patients initiating hemodialysis at for-profit and not-for-profit centers in the United States between 1998 and 2003. For-profit status of dialysis facilities was determined after subjects received 6 months of dialysis therapy, and mean follow-up was I.7 years.

Results: Of the study population $(N=205,076), 79.9 \%$ were dialyzed in for-profit facilities after 6 months of dialysis therapy. Dialysis at for-profit facilities was associated with higher urea reduction ratios, hemoglobin levels (including levels above 12 and $13 \mathrm{~g} / \mathrm{dL}$ [ 120 and I30 g/L]), epoetin doses, and use of intravenous iron, and less use of blood transfusions and lower proportions of patients on the transplant waiting-list $(P<0.05)$. Patients dialyzed at for-profit and at not-for-profit facilities had similar mortality risks (adjusted hazards ratio $1.02,95 \% \mathrm{Cl} 0.99-1.06, P=0.143$ ).

Conclusion: While hemodialysis treatment at for-profit and not-for-profit dialysis facilities is associated with different patterns of clinical benchmark achievement, mortality rates are similar.

\section{Background}

The incidence rate of treated end-stage renal disease (ESRD) has increased fourfold in the last quarter century [1]. In 2003, the cost to the US Medicare program for a typical dialysis patient was estimated at $\$ 67,000$ and ESRD accounted for $6.7 \%$ of all Medicare expenditures, compared with $4.8 \%$ in 1991 [1]. Reimbursement for dialysis services, which has changed little since 1982, is delivered on a per-treatment basis, irrespective of medical, logistical, and infrastructure complexities; cost containment has been a concern since the early days of the Medicare ESRD program [2]. Not surprisingly, for-profit dialysis facilities have become the norm, with freestand- 
ing, private, chain-affiliated facilities exhibiting the most prolific growth [1].

The concern that treatment at for-profit dialysis facilities may be associated with lower survival rates has been debated for decades [3-12]. Two comparatively recent studies $[8,12]$ demonstrated higher mortality rates at forprofit than at not-for-profit dialysis facilities, leading to national and international debate [13-17]. The first of these studies [8] examined a nationally representative sample of United States patients on hemodialysis at the end of 1990 and 1993; the second study [12] included patients from Michigan in 1973 through 1981, and patients on dialysis in the United States in 1990 and in 1993 through 1997. More recently, mortality was related to for-profit status in national random samples of patients receiving hemodialysis therapy in the United States at the beginning of 1994 through 2000 [18]. In the last of these studies, while unadjusted analysis showed no differences in mortality, adjustment for age, demography, cause of renal disease, and on-therapy clinical benchmarks showed higher mortality hazards ratio for patients treated at for-profit facilities [18]. The possibility that dialysis at for-profit facilities, where 4 of every 5 dialysis patients receive care [1] may be associated with a survival disadvantage has not been examined in more recent cohorts beginning dialysis therapy in the US. Our study was an attempt to address this issue.

\section{Methods \\ Objectives}

Our primary objective was to compare the mortality rates of patients starting hemodialysis at for-profit and at notfor-profit hemodialysis facilities in the United States between 1998 and 2003. Secondary objectives included comparison of clinical benchmarks according to for-profit or not-for-profit status.

\section{Design}

The United States Renal Data System (USRDS) generally recommends beginning outcome analyses after 90 days have elapsed since the first dialysis treatment (the 90-day rule), partly to allow time to establish a stable dialysis choice and partly because in-center hemodialysis patients aged less than 65 years cannot bill Medicare for their dialysis treatments until 90 days have elapsed [1]. Thus, for this study, the starting date was the 91st day after dialysis inception. Two phases were then constructed, with the first 3 months of the study (the exposure period) used to characterize the study population, including assessment of clinical benchmarks, and subsequent follow-up time (the outcome period) used to assess mortality.

\section{Study Population}

We used the 100\% ESRD sample from the Medicare database to select patients who were first dialyzed between January 1, 1998, and December 31, 2003; had Medicare as primary payer throughout the exposure period; and were on hemodialysis at either a for-profit or not-for-profit dialysis facility at the end of the exposure period.

Patient demographics were obtained from the ESRD Medical Evidence Report (Centers for Medicare \& Medicaid Services [CMS] form CMS-2728-U4), which is filed for all patients initiating maintenance dialysis. Medicare claims generated during the exposure period were used as supplementary data sources to identify comorbid conditions. Comorbid conditions from Medicare Part A institutional and Part B physician/supplier claims were identified by International Classification of Diseases, Ninth Revision, Clinical Modification (ICD-9-CM) codes and Current Procedural Terminology (CPT) codes. Comorbid conditions were considered present if an affirmative response was present in the Medical Evidence Report or on Medicare Part A or Part B claims. Cumulative hospital days and infectious hospitalization admissions in the exposure period were also determined from Medicare inpatient claim files. Clinical benchmarks, including hemoglobin levels, epoetin doses, urea reduction ratios, intravenous iron use, and blood transfusions, were obtained from Medicare institutional outpatient claims; wait-listing for renal transplant was obtained from the USRDS database. Vital status was obtained from the CMS ESRD Death Notification (form CMS-2746-U3), and renal transplantation from the USRDS database.

Dialysis facility profit status (for-profit or not-for-profit) and facility status (freestanding or hospital-based) were determined from the CMS Annual Facility Survey. Dialysis facilities can change their profit status, and patients can change dialysis facilities. We applied the USRDS 60-day collapsing rule to such changes, namely, that they must remain in place for at least 60 days to be considered stable [1].

\section{Analysis}

Follow-up began immediately after the exposure period, and ended at the earliest occurrence of 3 years elapsed, death, renal transplantation, loss to follow-up, or December 31,2004 . The characteristics of patients receiving dialysis at for-profit and not-for-profit dialysis units were compared using the chi squared test for categorical variables and multivariate logistic regression. Cox proportional hazards regression was used to quantify the mortality hazards ratios. The robust standard error method was used to account for the possibility of clustering of patients within dialysis facilities [19]. All analyses were performed using SAS version 9.1 (SAS Institute, Inc., Cary, NC). 
Table I: Baseline Characteristics

\begin{tabular}{|c|c|c|c|c|c|c|}
\hline \multirow[b]{2}{*}{ Characteristic } & \multirow[b]{2}{*}{$\begin{array}{c}\text { All, } 100.0 \% \\
N=205,076\end{array}$} & \multicolumn{2}{|c|}{ Facility Profit Status } & \multirow[b]{2}{*}{$p^{*}$} & \multirow[b]{2}{*}{ AOR For-Profit $(95 \% \mathrm{Cl})$} & \multirow[b]{2}{*}{$P^{\dagger}$} \\
\hline & & $\begin{array}{c}\text { Not-For-Profit, } \\
20.1 \% n=41,307\end{array}$ & $\begin{array}{c}\text { For-Profit, } 79.9 \% \\
n=163,769\end{array}$ & & & \\
\hline Facility affiliation & & & & $<0.0001$ & & \\
\hline Freestanding & 12.9 & 41.4 & 98.6 & & Reference & - \\
\hline Hospital-based & 87.1 & 58.6 & 1.4 & & $0.01(0.01-0.01)$ & $<0.0001$ \\
\hline Year of dialysis inception & & & & $<0.0001$ & & \\
\hline 1998 & 14.7 & 18.5 & 13.7 & & Reference & - \\
\hline 1999 & 15.4 & 17.6 & 14.8 & & $1.16(1.10-1.23)$ & $<0.0001$ \\
\hline 2000 & 16.6 & 17.8 & 16.3 & & $1.12(1.06-1.19)$ & $<0.0001$ \\
\hline 2001 & 17.0 & 16.0 & 17.3 & & $1.06(1.00-1.12)$ & 0.032 \\
\hline 2002 & 17.8 & 15.6 & 18.3 & & $0.87(0.83-0.92)$ & $<0.0001$ \\
\hline 2003 & 18.4 & 14.4 & 19.5 & & $0.89(0.85-0.94)$ & $<0.0001$ \\
\hline Age group (years) & & & & $<0.0001$ & & \\
\hline$\leq 40$ & 7.1 & 7.7 & 7.0 & & Reference & - \\
\hline 40 to 65 & 33.7 & 32.1 & 34.1 & & $1.10(1.04-1.17)$ & 0.002 \\
\hline$>65$ & 59.1 & 60.2 & 58.9 & & $1.14(1.06-1.22)$ & 0.0002 \\
\hline Sex & & & & $<0.0001$ & & \\
\hline Male & 52.0 & 53.3 & 51.7 & & $0.98(0.95-1.01)$ & 0.280 \\
\hline Female & 48.0 & 46.7 & 48.3 & & Reference & - \\
\hline Race & & & & $<0.0001$ & & \\
\hline White & 62.6 & 64.9 & 62.0 & & Reference & - \\
\hline Black & 32.4 & 29.1 & 33.2 & & $0.91(0.88-0.95)$ & 0.001 \\
\hline Other & 5.1 & 5.9 & 4.8 & & $0.96(0.90-1.03)$ & 0.297 \\
\hline Body mass index $\left(\mathrm{kg} / \mathrm{m}^{2}\right)$ & & & & $<0.0001$ & & \\
\hline$<18.5$ & 5.9 & 6.4 & 5.8 & & $0.90(0.84-0.96)$ & 0.001 \\
\hline 18.5 to $<25$ & 38.7 & 39.0 & 38.6 & & Reference & - \\
\hline 25 to $<30$ & 28.3 & 28.2 & 28.3 & & $1.02(0.98-1.06)$ & 0.358 \\
\hline$\geq 30$ & 27.1 & 26.4 & 27.3 & & $1.04(1.00-1.08)$ & 0.074 \\
\hline Employment status & & & & $<0.0001$ & & \\
\hline Employed & 10.4 & 10.6 & 10.3 & & Reference & - \\
\hline Unemployed & 43.7 & 41.1 & 44.4 & & $0.96(0.91-1.01)$ & 0.093 \\
\hline Retired & 45.9 & 48.4 & 45.3 & & $0.89(0.84-0.94)$ & $<0.0001$ \\
\hline Cause of ESRD & & & & $<0.0001$ & & \\
\hline Diabetes mellitus & 48.7 & 47.6 & 49.0 & & Reference & - \\
\hline Hypertension & 30.8 & 28.4 & 31.4 & & $1.09(1.05-1.13)$ & $<0.0001$ \\
\hline Glomerulonephritis & 7.9 & 9.1 & 7.6 & & $0.91(0.86-0.97)$ & 0.002 \\
\hline Other & 12.6 & 14.9 & 12.0 & & $0.92(0.87-0.96)$ & 0.0003 \\
\hline Hospitalization (days) & & & & $<0.0001$ & & \\
\hline 0 & 65.9 & 65.6 & 66.0 & & Reference & - \\
\hline 0 to 5 & 15.6 & 15.1 & 15.7 & & $1.04(0.99-1.09)$ & 0.110 \\
\hline$>5$ & 18.5 & 19.3 & 18.3 & & $1.16(1.10-1.22)$ & $<0.0001$ \\
\hline Infectious hospitalization & 10.6 & 11.1 & 10.5 & 0.0011 & $0.94(0.89-1.00)$ & 0.036 \\
\hline $\begin{array}{l}\text { Atherosclerotic heart } \\
\text { disease }\end{array}$ & 40.1 & 42.8 & 39.4 & $<0.0001$ & $0.93(0.90-0.97)$ & 0.0001 \\
\hline Congestive heart failure & 45.0 & 46.2 & 44.7 & $<0.0001$ & $1.04(1.00-1.07)$ & 0.043 \\
\hline Stroke or TIA & 16.0 & 16.5 & 15.9 & 0.0043 & $0.98(0.94-1.02)$ & 0.247 \\
\hline Peripheral vascular disease & 27.5 & 29.4 & 27.1 & $<0.0001$ & $0.99(0.96-1.03)$ & 0.718 \\
\hline Dysrhythmia & 18.8 & 20.5 & 18.3 & $<0.0001$ & $0.91(0.87-0.95)$ & $<0.0001$ \\
\hline Other cardiac disease & 13.1 & 13.5 & 13.0 & 0.0223 & $1.02(0.98-1.07)$ & 0.347 \\
\hline COPD & 14.0 & 15.4 & 13.6 & $<0.0001$ & $0.88(0.84-0.92)$ & $<0.0001$ \\
\hline Gastrointestinal disease & 4.3 & 4.7 & 4.1 & $<0.0001$ & $0.96(0.89-1.04)$ & 0.311 \\
\hline Hepatic disease & 8.6 & 6.8 & 9.1 & $<0.0001$ & $1.51(1.42-1.60)$ & $<0.0001$ \\
\hline Cancer & 8.8 & 9.6 & 8.6 & $<0.0001$ & $0.94(0.89-0.99)$ & 0.022 \\
\hline \multicolumn{7}{|l|}{ Clinical benchmarks } \\
\hline $\begin{array}{l}\text { Urea reduction ratio } \\
(\%)\end{array}$ & & & & $<0.0001$ & & \\
\hline$<60$ & 8.3 & 9.3 & 8.1 & & $0.93(0.87-0.99)$ & 0.019 \\
\hline 60 to $<65$ & 11.7 & 12.0 & 11.7 & & Reference & - \\
\hline 65 to $<70$ & 21.7 & 20.0 & 22.1 & & $1.20(1.14-1.27)$ & $<0.0001$ \\
\hline
\end{tabular}


Table I: Baseline Characteristics (Continued)

\begin{tabular}{|c|c|c|c|c|c|c|}
\hline 70 to $<75$ & 24.3 & 21.0 & 25.2 & & $1.22(1.16-1.29)$ & $<0.0001$ \\
\hline$\geq 75$ & 20.8 & 17.2 & 21.7 & & $1.17(1.11-1.24)$ & 0.0002 \\
\hline Unknown & 13.1 & 20.4 & 11.3 & & - & - \\
\hline Hemoglobin $(\mathrm{g} / \mathrm{dL})^{\ddagger}$ & & & & $<0.0001$ & & \\
\hline$<10$ & 7.6 & 8.9 & 7.3 & & $0.89(0.84-0.95)$ & 0.0002 \\
\hline 10 to $<11$ & 14.6 & 15.8 & 14.3 & & $0.96(0.92-1.01)$ & 0.080 \\
\hline 11 to $<12$ & 28.7 & 28.7 & 28.6 & & Reference & - \\
\hline 12 to $<13$ & 24.9 & 20.3 & 26.1 & & $1.23(1.19-1.29)$ & $<0.0001$ \\
\hline$\geq 13$ & 13.3 & 9.3 & 14.3 & & $1.66(1.57-1.75)$ & $<0.0001$ \\
\hline Unknown & 10.9 & 16.9 & 9.3 & & - & - \\
\hline $\begin{array}{l}\text { Epoetin dose quartiles } \\
\text { (units/month) }\end{array}$ & & & & $<0.0001$ & & \\
\hline$<35,766$ & 22.3 & 23.3 & 22.0 & & Reference & - \\
\hline 35,766 to $<58,200$ & 22.4 & 22.3 & 22.4 & & $0.96(0.92-1.00)$ & 0.050 \\
\hline 58,200 to $<91,250$ & 22.3 & 20.0 & 22.9 & & $1.06(1.02-1.11)$ & 0.009 \\
\hline$\geq 91,250$ & 22.3 & 17.7 & 23.4 & & $1.16(1.10-1.21)$ & $<0.0001$ \\
\hline Unknown & 10.8 & 16.7 & 9.3 & & - & - \\
\hline Intravenous iron use & 71.1 & 60.1 & 73.9 & $<0.0001$ & $1.23(1.19-1.27)$ & $<0.0001$ \\
\hline Blood transfusion & 6.3 & 6.8 & 6.2 & $<0.0001$ & $0.93(0.87-0.99)$ & 0.025 \\
\hline On transplant waiting list & 2.7 & 3.6 & 2.5 & $<0.0001$ & $0.75(0.69-0.82)$ & $<0.0001$ \\
\hline
\end{tabular}

Values are percentage of $n$ in column head. AOR, adjusted odds ratio; COPD, chronic obstructive pulmonary disease; ESRD, end-stage renal disease; TIA, transient ischemic attack.

*Compared using the $\chi^{2}$ test.

tUsing multiple logistic regression, with adjustment for facility affiliation, year of dialysis inception, age group, sex, race, body mass index, employment status, cause of ESRD, days of hospitalization, infectious hospitalization, and comorbid conditions.

劺 convert hemoglobin in $\mathrm{g} / \mathrm{dL}$ to $\mathrm{g} / \mathrm{L}$, multiply by 10 .

\section{Results}

In all, 258,774 patients were eligible for analysis. Of these, facility characteristics were unknown for 26,455 . For another 27,243 patients, information was lacking on date of birth, sex, race, primary renal disease, body mass index, or employment status. Hence, the final sample size was 205,076.

After 6 months of dialysis therapy, $79.9 \%$ of the sample was dialyzed at one of 3632 for-profit facilities, and $20.1 \%$ at one of 1264 not-for-profit facilities. Table 1 shows the characteristics of the overall study population and a comparison of patients in for-profit and not-forprofit facilities. On multivariate analysis, the characteristics associated with therapy at for-profit facilities were as follows: freestanding units; more recent calendar year; age $\leq 65$ years; female sex; non-white race; overweight; fewer retirees; diabetes and hypertension as primary causes of renal disease; hospitalization days during the exposure period; fewer infectious hospitalizations; absence of atherosclerotic heart disease, dysrhythmia, chronic obstructive primary disorder, and cancer; and presence of congestive heart failure and hepatic disease.

Regarding clinical benchmarks after 6 months of dialysis therapy, on bivariate and multivariate analyses, patients at for-profit facilities had higher urea reduction ratios, higher hemoglobin levels (including levels above 12 and $13 \mathrm{~g} / \mathrm{dL}$ [120 and $130 \mathrm{~g} / \mathrm{L}]$ ), more frequent use of intrave- nous iron, less frequent use of blood transfusions, and a lower proportion on the transplant waiting list (Table 1).

The overall crude mortality rate was 25.6 per 100 patientyears at risk, over a 1.7-year average duration of follow-up. Unadjusted mortality risk was higher for patients dialyzed at for-profit facilities (hazards ratio 0.89 compared with not-for-profit facilities, 95\% confidence interval [CI] $0.87-0.92, P<0.0001)$. Table 2 shows adjusted mortality associations from proportional hazards regression models. Patients dialyzed at for-profit and at not-for-profit facilities had similar mortality risks (adjusted hazards ratio [AHR] 1.02, 95\% CI 0.99-1.06, $P=0.143$ ). In contrast, mortality risk was higher for patients dialyzed at hospital-based facilities (AHR 1.18, 95\% CI 1.14-1.23, P $<0.0001$ ), compared with freestanding facilities.

\section{Discussion}

Using an inception cohort design spanning the years 1998 to 2003, we found similar mortality risks in patients dialyzed at for-profit and at not-for-profit facilities. For-profit status was associated with each of the clinical benchmarks studied. Thus, patients at for-profit facilities had higher urea reduction ratios, higher hemoglobin levels (including levels above recommended targets), more frequent use of intravenous iron, less frequent use of blood transfusions, and a lower proportion on the transplant waiting list. 
Table 2: Mortality Hazards Ratios

\begin{tabular}{|c|c|c|}
\hline Characteristic & Adjusted* Hazards Ratios $(95 \% \mathrm{Cl})$ & $P$ \\
\hline \multicolumn{3}{|l|}{ Facility profit status } \\
\hline Not-for-profit & Reference & - \\
\hline For-profit & $1.02(0.99-1.06)$ & 0.143 \\
\hline \multicolumn{3}{|l|}{ Facility affiliation } \\
\hline Freestanding & Reference & - \\
\hline Hospital-based & $1.18(1.14-1.23)$ & $<0.0001$ \\
\hline \multicolumn{3}{|l|}{ Year of dialysis inception } \\
\hline 1998 & Reference & - \\
\hline 1999 & $1.00(0.97-1.02)$ & 0.707 \\
\hline 2000 & $1.04(1.01-1.07)$ & 0.003 \\
\hline 2001 & $1.03(1.00-1.06)$ & 0.035 \\
\hline 2002 & $1.03(1.00-1.06)$ & 0.046 \\
\hline 2003 & $1.01(0.98-1.04)$ & 0.724 \\
\hline \multicolumn{3}{|l|}{ Age group (years) } \\
\hline$\leq 40$ & Reference & - \\
\hline 40 to 65 & $1.50(1.44-1.57)$ & $<0.0001$ \\
\hline$>65$ & $2.34(2.23-2.45)$ & $<0.0001$ \\
\hline \multicolumn{3}{|l|}{ Sex } \\
\hline Male & $0.97(0.96-0.99)$ & $<0.0001$ \\
\hline Female & Reference & - \\
\hline \multicolumn{3}{|l|}{ Race } \\
\hline White & Reference & - \\
\hline Black & $0.78(0.77-0.80)$ & $<0.0001$ \\
\hline Other & $0.76(0.72-0.81)$ & $<0.0001$ \\
\hline \multicolumn{3}{|l|}{ Body mass index $\left(\mathrm{kg} / \mathrm{m}^{2}\right)$} \\
\hline$<18.5$ & $1.21(1.17-1.25)$ & $<0.0001$ \\
\hline 18.5 to $<25$ & Reference & - \\
\hline 25 to $<30$ & $0.84(0.82-0.85)$ & $<0.0001$ \\
\hline$\geq 30$ & $0.76(0.75-0.78)$ & $<0.0001$ \\
\hline \multicolumn{3}{|l|}{ Employment status } \\
\hline Employed & Reference & - \\
\hline Unemployed & $1.20(1.15-1.24)$ & $<0.0001$ \\
\hline Retired & $1.22(1.18-1.27)$ & $<0.0001$ \\
\hline \multicolumn{3}{|l|}{ Cause of ESRD } \\
\hline Diabetes mellitus & Reference & - \\
\hline Hypertension & $0.89(0.88-0.91)$ & $<0.0001$ \\
\hline Glomerulonephritis & $0.73(0.7 \mathrm{I}-0.76)$ & $<0.0001$ \\
\hline Other & $0.99(0.97-1.02)$ & 0.490 \\
\hline \multicolumn{3}{|l|}{ Hospitalization (days) } \\
\hline 0 & Reference & - \\
\hline 0 to 5 & $1.13(1.11-1.16)$ & $<0.0001$ \\
\hline$>5$ & $1.54(1.50-1.57)$ & $<0.0001$ \\
\hline Infectious hospitalization & $1.13(1.10-1.16)$ & $<0.0001$ \\
\hline Atherosclerotic heart disease & $1.06(1.04-1.08)$ & $<0.0001$ \\
\hline Congestive heart failure & $1.33(1.31-1.36)$ & $<0.0001$ \\
\hline Stroke or TIA & $1.19(1.17-1.21)$ & $<0.0001$ \\
\hline Peripheral vascular disease & $1.16(1.14-1.17)$ & $<0.0001$ \\
\hline Dysrhythmia & $1.25(1.23-1.28)$ & $<0.0001$ \\
\hline Other cardiac disease & $1.07(1.05-1.10)$ & $<0.0001$ \\
\hline COPD & $1.23(1.21-1.26)$ & $<0.0001$ \\
\hline Gastrointestinal disease & $1.21(1.17-1.25)$ & $<0.0001$ \\
\hline Hepatic disease & $1.07(1.03-1.10)$ & $<0.0001$ \\
\hline Cancer & $\mathrm{I} .44(\mathrm{I} .4 \mathrm{I}-\mathrm{I} .48)$ & $<0.0001$ \\
\hline
\end{tabular}

COPD, chronic obstructive pulmonary disease; ESRD, end-stage renal disease. TIA, transient ischemic attack

*Using proportional hazards regression with adjustment for for-profit status, facility affiliation, year of dialysis inception, age group, sex, race, body mass index, employment status, cause of ESRD, days of hospitalization, infectious hospitalization, and comorbid conditions. 
With an average cost per dialysis patient to Medicare of $\$ 67,000$ per year in 2002 [1] dialysis is undoubtedly an expensive therapy. The question of whether profit motives could compromise care for dialysis patients seems reasonable. Examining this issue regularly also seems reasonable, given that the treatment of dialysis patients continues to change rapidly. Recent national studies found associations between for-profit facility status and patient mortality different from the associations seen in this study. The first of these studies examined the question in a nationally representative sample of patients on hemodialysis in the United States at the end of 1990 and at the end 1993 [8]. The subset of patients receiving renal replacement therapy for more than 90 days and less than 1 year was chosen, and facility profit status was treated as a time-dependent variable. Treatment at a for-profit dialysis facility was associated with higher mortality hazards, the point estimate being 20\% (95\% CI 25-42\%) higher than that in not-for-profit facilities [8].

The second study, a meta-analysis spanning 1973 to 1997 , concluded that relative mortality rates were $8 \%$ higher at private, for-profit than at private, not-for-profit dialysis facilities [12]. The 8 studies included (4 peer-reviewed publications, 3 dissertations, 1 letter to an editor) were heterogeneous with regard to patient selection, covariate adjustment, and the methods used to generate comparative risk estimates. Twelve studies were not incorporated in the risk estimate because they included patients on treatment at public facilities and because the original authors were unable to perform analyses that excluded these patients. Interestingly, the overwhelming majority of patients considered for inclusion in the meta-analysis came from a single, publicly available dataset, the USRDS dataset. A de novo analysis of all available patients might provide useful information, such as homogeneous inclusion criteria and analytical methods, and the ability to include, exclude, or adjust for potential confounders, such as dialysis at public or private facilities. One potential explanation that could harmonize our findings with those from older studies is the possibility that quality of care has improved more in for-profit facilities over time than in not-for-profit or hospital-based facilities.

The most recent study related profit status to mortality in national random samples of US patients receiving hemodialysis therapy at the beginning of the years 1994 through 2000. Unadjusted analysis showed no mortality differences, but when adjustment was made for demography, cause of renal disease, and, notably, clinical benchmarks, higher mortality hazards ratios were seen for therapy at for-profit facilities; as in our study, patients in for-profit facilities had higher urea reduction ratios and hemoglobin values than those in not-for-profit facilities [18].
It is highly implausible that the primary research question addressed here could ever be addressed with a randomized controlled trial. That being said, the current study unquestionably suffers from all limitations inherent to observational designs. Thus, while identification of highrisk populations is possible, accurate delineation of causal pathways is not. Despite its limitations, we believe that this study offers useful information. The sample size was large, and a national-level population was examined over several years. Consequently, one methodology was applied consistently, to all patients, in all years. The study included relatively contemporary patient cohorts. It used publicly available data, so others can explore the validity of the approaches used, now and in the future.

\section{Conclusion}

Our findings suggest that, in contemporary hemodialysis patients in the United States, treatment at for-profit and at not-for-profit dialysis facilities is associated with similar mortality rates.

\section{Competing interests}

The authors declare that they have no competing interests.

\section{Authors' contributions}

Study conception and design: RNF, JL, DTG, S-CC, AJC. Acquisition of data: S-CC, AJC. Analysis and interpretation of data: RNF, QF, JL, DTG, EDW, S-CC, AJC. Drafting the manuscript: RNF. Revising the manuscript critically for important intellectual content: QF, JL, DTG, EDW, SCC, AJC.

\section{Acknowledgements}

The data reported here have been supplied by the United States Renal Data System. This study was performed as a deliverable under Contract No. HHSN267200715002C (National Institute of Diabetes and Digestive and Kidney Diseases, National Institutes of Health, Bethesda, Maryland). The authors thank James Kaufmann, PhD, and Nan Booth, MSW, MPH, for editorial assistance; Dana D. Knopic for help in preparing and submitting the manuscript; and Beth Forrest for regulatory assistance in the operation of the United States Renal Data System Coordinating Center.

\section{References}

I. U.S. Renal Data System: USRDS 2006 Annual Data Report Bethesda, MD: National Institutes of Health, National Institute of Diabetes and Digestive and Kidney Diseases; 2006.

2. Evans RW, Blagg CR, Bryan FA Jr: Implications for health care policy. A social and demographic profile of hemodialysis patients in the United States. JAMA I98I, 245:487-49I.

3. Lowrie EG, Hampers CL: The success of Medicare's end-stage renal-disease program: the case for profits and the private marketplace. N Engl J Med I98I, 305:434-438.

4. Held P, Pauly M, Diamond L: Survival analysis of patients undergoing dialysis. JAMA 1987, 257(5):645-650.

5. Schlesinger M, Cleary PD, Blumenthal D: The ownership of health facilities and clinical decisionmaking. The case of the ESRD industry. Med Care 1989, 27:244-258.

6. Collins AJ, Ma J, Constantini E, Everson S: Dialysis unit and patient characteristics associated with reuse practices and mortality: 1989-1993. J Am Soc Nephrol 1998, 9(I I):2108-21 I7. 
7. McClellan WM, Soucie JM, Flanders WD: Mortality in end-stage renal disease is associated with facility-to-facility differences in adequacy of hemodialysis. J Am Soc Nephrol 1998, 9:1940- 1947.

8. Garg PP, Frick KD, Diener-West M, Powe NR: Effect of the ownership of dialysis facilities on patients' survival and referral for transplantation. N Engl J Med 1999, 34I:1653-1660.

9. Port FK, Wolfe RA, Held PJ: Ownership of dialysis facilities and patients' survival. N Engl J Med 2000, 342: I053-1054.

10. Nissenson AR, Owen WF Jr: Ownership of dialysis facilities and patients' survival. N Engl J Med 2000, 342: $1054-1055$.

II. Frankenfield DL, Sugarman JR, Presley RJ, Helgerson SD, Rocco MV: Impact of facility size and profit status on intermediate outcomes in chronic dialysis patients. Am J Kidney Dis 2000, 36:318-326.

12. Devereaux PJ, Schunemann HJ, Ravindran N, Bhandari M, Garg AX Choi PT, et al.: Comparison of mortality between private forprofit and private not-for-profit hemodialysis centers: a systematic review and meta-analysis. JAMA 2002, 288:2449-2457.

13. Josefson D: Patients dialysed at for-profit centres do worse. BMJ 1999, $319: 1517$.

14. Canadian Health Services Research Foundation: Myth: For-profit ownership of facilities would lead to a more efficient healthcare system. Canadian Health Services Research Foundation 2004 [http://www.chsrf.ca/mythbusters/html/myth /3 e.php]. II-19-2004. Ref Type: Electronic Citation

15. Kalantar-Zadeh K, Mehrotra R, Kopple JD: Quality of care in profit vs not-for-profit dialysis centers. JAMA 2003, 289:3089-3090.

16. Blake PG, Mendelssohn DC: Quality of care in profit vs not-forprofit dialysis centers. JAMA 2003, 289:3088-3089.

17. Bosch J, Hakim RM, Lazarus JM, McAllister CJ: Quality of care in profit vs not-for-profit dialysis centers. JAMA 2003, 289:3087-3088.

18. Szczech LA, Klassen PS, Chua B, Hedayati SS, Flanigan M, McClellan WM, et al: Associations between CMS's Clinical Performance Measures project benchmarks, profit structure, and mortality in dialysis units. Kidney Int 2006, 69:2094-2 100.

19. Lin D, Wei L: The robust inference for the Cox proportional hazards model. J Am Stat Assoc 1989, 84: 1074-1078.

\section{Pre-publication history}

The pre-publication history for this paper can be accessed here:

http://www.biomedcentral.com/1471-2369/9/6/prepub

Publish with Bio Med Central and every scientist can read your work free of charge

"BioMed Central will be the most significant development for disseminating the results of biomedical research in our lifetime. "

Sir Paul Nurse, Cancer Research UK

Your research papers will be:

- available free of charge to the entire biomedical community

- peer reviewed and published immediately upon acceptance

- cited in PubMed and archived on PubMed Central

- yours - you keep the copyright
BioMedcentral 